\title{
SH003 suppresses breast cancer growth by accumulating p62 in autolysosomes
}

\author{
Youn Kyung Choi ${ }^{1, *}$, Sung-Gook Cho ${ }^{2, *}$, Yu-Jeong Choi ${ }^{3}$, Yee Jin Yun ${ }^{3}$, Kang Min Lee ${ }^{4}$, \\ Kangwook Lee ${ }^{4}$, Hye-Hyun Yoo ${ }^{5}$, Yong Cheol Shin ${ }^{6}$ and Seong-Gyu Ko ${ }^{6}$ \\ ${ }^{1}$ Jeju International Marine Science Center for Research and Education, Korea Institute of Ocean Science and Technology \\ (KIOST), Jeju, 695-975, Korea \\ ${ }^{2}$ Department of Biotechnology, Korea National University of Transportation, Chungbuk, 368-701, Korea \\ ${ }^{3}$ Department of Cancer Preventive Material Development, Graduate School, Kyung Hee University, Seoul, 130-701, Korea \\ ${ }^{4}$ Department of Science in Korean Medicine, Graduate School, Kyung Hee University, Seoul, 130-701, Korea \\ ${ }^{5}$ Institute of Pharmaceutical Science and Technology and Collage of Pharmacy, Hanyang University, Gyonggi, 426-791, Korea \\ ${ }^{6}$ Laboratory of Clinical Biology and Pharmacogenomics, Department of Preventive Medicine, College of Korean Medicine, \\ Kyung Hee University, Seoul, 130-701, Korea \\ *These authors contributed equally to this work
}

Correspondence to: Seong-Gyu Ko, email: epiko@khu.ac.kr Keywords: SH003, breast cancer, autophagy, apoptosis, p62

Received: October 15, $2015 \quad$ Accepted: July 27, 2016

Published: August 19, 2016

Copyright: Choi et al. This is an open-access article distributed under the terms of the Creative Commons Attribution License 3.0 (CC BY 3.0), which permits unrestricted use, distribution, and reproduction in any medium, provided the original author and source are credited.

\section{ABSTRACT}

Drug markets revisits herbal medicines, as historical usages address their therapeutic efficacies with less adverse effects. Moreover, herbal medicines save both cost and time in development. SH003, a modified version of traditional herbal medicine extracted from Astragalus membranaceus (Am), Angelica gigas (Ag), and Trichosanthes Kirilowii Maximowicz (Tk) with 1:1:1 ratio $(w / w)$ has been revealed to inhibit tumor growth and metastasis on highly metastatic breast cancer cells, both in vivo and in vitro with no toxicity. Meanwhile, autophagy is imperative for maintenance cellular homeostasis, thereby playing critical roles in cancer progression. Inhibition of autophagy by pharmacological agents induces apoptotic cell death in cancer cells, resulting in cancer treatment. In this study, we demonstrate that SH003induced autophagy via inhibiting STAT3 and mTOR results in an induction of lysosomal p62/SQSTM1 accumulation-mediated reactive oxygen species (ROS) generation and attenuates tumor growth. SH003 induced autophagosome and autolysosome formation by inhibiting activation of STAT3- and mTOR-mediated signaling pathways. However, SH003 blocked autophagy-mediated p62/SQSTM1 degradation through reducing of Iysosomal proteases, Cathepsins, resulting in accumulation of p62/SQSTM1 in the lysosome. The accumulation of p62/SQSTM1 caused the increase of ROS, which resulted in the induction of apoptotic cell death. Therefore, we conclude that $\mathrm{SHOO}$ suppresses breast cancer growth by inducing autophagy. In addition, SH003-induced p62/SQSTM1 could function as an important mediator for ROS generation-dependent cell death suggesting that $\mathrm{SHOO3}$ may be useful for treating breast cancer.

\section{INTRODUCTION}

Balance between protein synthesis and degradation is important to maintain cellular homeostasis. Protein degradation in eukaryotic cells follows one of systems, either proteasomal or lysosomal degradation system $[1,2]$.
Autophagy requires complex molecular mechanisms. Autophagic vesicle engulfs protein aggregates, damaged organelles, bacteria and other molecules, fusing with lysosome to form autophagosome. This autophagic mechanism degrades macromolecules by lysosomal hydrolytic enzymes including glucuronidase, ribonuclease, 
acid phosphatase, sulfatase and collagenase, and recycles constituent amino acids [3, 4]. So, when cells lack nutrients, autophagy is induced to supply nutrient for cell growth, metabolism and survival [2]. Alterations in autophagy occur in various diseases including vascular instability [5], metabolic dysfunction [6], cardiomyopathies and myopathies $[7,8]$, neurodegeneration [9], non-alcoholic fatty liver disease [10] and Crohn's disease [11]. In addition, autophagy has an critical role in cancer [12]. While autophagy prevents tumorigenesis by inhibiting an accumulation of damagedorganelles and misfolded-proteins in normal cells, it activates cancer development by increasing tumor cell survival mechanism [13]. Moreover, autophagy regulates distant metastases of cancer cells $[14,15]$. Therefore, targeting autophagy is important in cancer treatment [16-20].

Therefore, we recently developed a new herbal medicine named $\mathrm{SH003}$ on the basis of the theory of the traditional Chinese medicine, and reported that it has an anti-cancer effect [21]. SH003 consists Astragalus membranaceus (Am), Angelica gigas (Ag), and Trichosanthes Kirilowii Maximowicz (Tk). Several studies showed that each herb has anti-cancer effects in different cancer cell types such as myeloid tumor [22], colon cancer [23], prostate cancer [24], liver cancer [25], non-small cell lung cancer [26] and breast cancer [27]. Nevertheless, it is yet unclear whether each herbal component or $\mathrm{SH} 003$ prevents cancer growth via autophagy. Here, we found that $\mathrm{SH} 003$ induced autophagy-mediated apoptosis through p62 accumulationmediated ROS generation, thereby suggesting that SH003 may be useful for treating cancer.

\section{RESULTS}

\section{SH003 induces apoptosis of breast cancer cells}

Breast cancer cells were treated with different concentrations $(0,100,250$ and $500 \mu \mathrm{g} / \mathrm{ml})$ of SH003 for 48 hours and then subjected to cell viability assays. SH003 inhibited both MDA-MB-231 and HCC-38 breast cancer cell viabilities (Figure 1A). Our live and dead assays confirmed that SH003 increased dead cell numbers (Figure 1B). Furthermore, SH003 increased Annexin V-positive apoptotic cell numbers in a dosedependent manner (Figure 1C). SH003 also altered Bax/ $\mathrm{Bcl} 2$ ratio and induced cleavages of Caspase- 3 and PARP (Figure 1D). Therefore, our data confirmed that SH003 induces apoptosis of breast cancer cells, consistently with our previous study [21].

\section{SH003 induces autophagy by inhibiting STAT3}

Our previous study found that SH003 targeted STAT3 in breast cancer cells [21]. Consistently, our present study confirmed SH003 inhibition of STAT3 phosphorylation in different breast cancer cells (Figure 2A). STAT3 has been known to regulate autophagy, which is crucial for cancer development [28-30]. We further examined whether SH003 affects autophagy by altering beclin1 interaction with STAT3 and autophagy associated proteins including VPS34 and Bcl-2. In our beclin1 immunoprecipitation assays, SH003 reduced beclin1 interaction with STAT3, VPS34 and Bcl-2 (Figure 2B), suggesting that SH003 might affect autophagy via disrupting beclin1 interaction with STAT3 and autophagy-associated proteins. Therefore, we further examined whether SH003 affect autophagy. SH003 induced autophagy, when cells were treated with SH003 for 24 hours and then stained with Cyto-ID fluorescence dye (a marker for autophagic vacuoles [31]) (Figure 2C). Supportively, SH003 increased the number of LC3 puncta per cell (Figure 2D) and altered LC3A/B ratio (Figure 2E). However, we unexpectedly found that SH003 increased a level of p62 (Figure 2E), while it has been revealed that autolysosome-dependent degradation system regulates p62 level [13, 32]. Thus, those data suggested that SH003 might induce autophagy with no effect on later stages such as autolysosome formation or autolysosomal degradation system. Moreover, constitutively active STAT3 (STAT3-CA) partly rescued that SH003 effect on autophagy (Figure 2F). Therefore, our data indicated that SH003 might induce autophagy by inhibiting STAT3 activation.

\section{SH003 induces autolysosome formation}

To test our hypothesis that $\mathrm{SH} 003$ induces autophagy with halting either autolysosome formation or autolysosomal degradation system, autosomal vacuoles were distinguished in terms of GFP-mCherryLC3B vector system. In this system, autophagosomes are visualized in yellow as they express both GFP and mCherry. Autolysosomes are colored in red as those express mCherry alone. SH003 increased numbers of both autophagosomes and autolysosomes (Figure 3A). Lysotracker red is a fluorescent dye that selectively accumulates in acidic vesicles such as lysosomes [33]. SH003 also induced co-localization of LC3B with lysotracker red (Figure 3B). Likewise, SH003 increased LC3B co-localization with lysosomal membrane protein, LAMP1 or LAMP2 (Figure 3C and 3D). Therefore, we concluded that SH003 induced autophagy but might affect autolysosomal degradation system, since it rather increased p62 level.

\section{Rapamycin enhances $\mathrm{SHO03}$ effect on autophagy-mediated apoptosis}

SH003 reduced phosphorylation of mTOR (major repressor autophagy [34]) and p70S6K (mTOR downstream target [35]) (Figure 4A). Moreover, 
autophagy was more increased when cells were treated with both SH003 and rapamycin (Figure 4B). Consistently, SH003 with rapamycin strongly increased autolysosome numbers (Figure 4C). Moreover, SH003 with rapamycin strongly induced apoptosis (Figure 4D). Those data support our finding that SH003 induces autophagy, and suggest that SH003 may affect other signaling pathways beyond rapamycin target, mTOR-mediated signaling.
SH003-mediated p62 accumulation via reduction of Cathepsin level in autolysosomes causes autophagy-mediated apoptosis

p62, a specific substrate of autophagy, is degraded in autolysosomes. Cells were treated with SH003 or autophagy inhibitors such as bafilomycin A1 (vacuolartype $\mathrm{H}(+)$-ATPase inhibitor [36]) and chloroquine
A

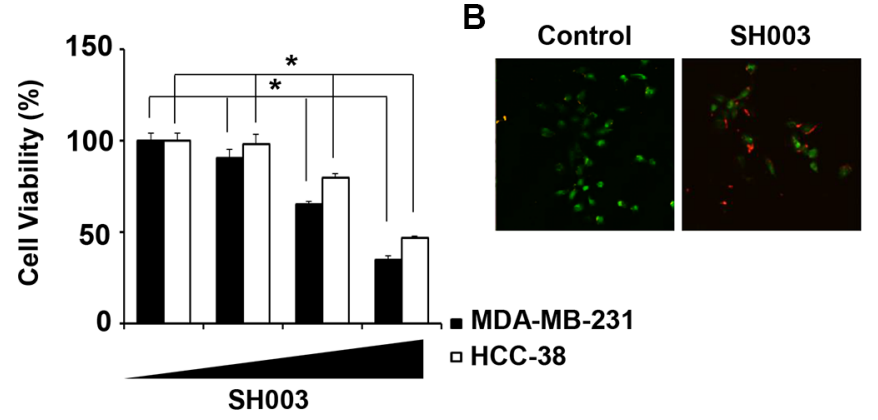

C

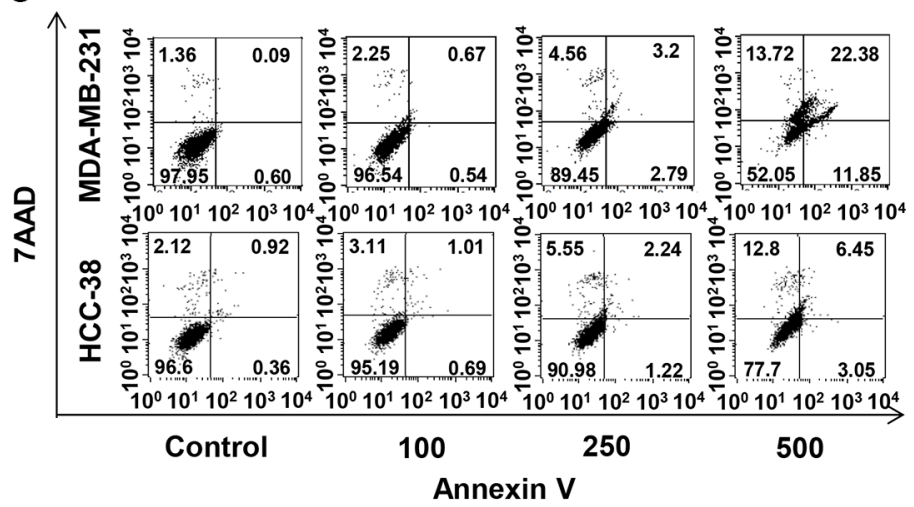

D
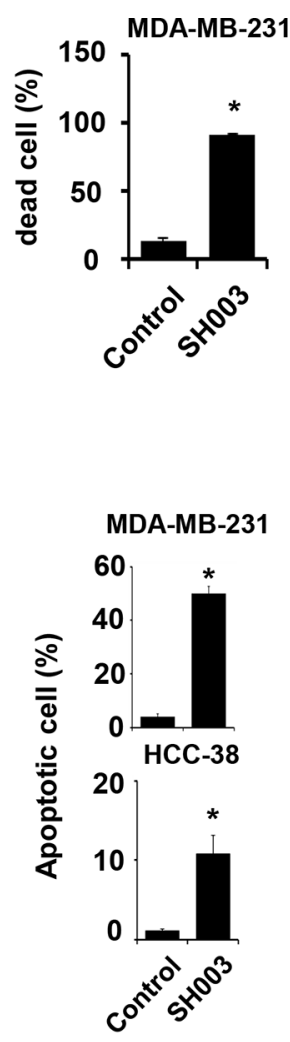

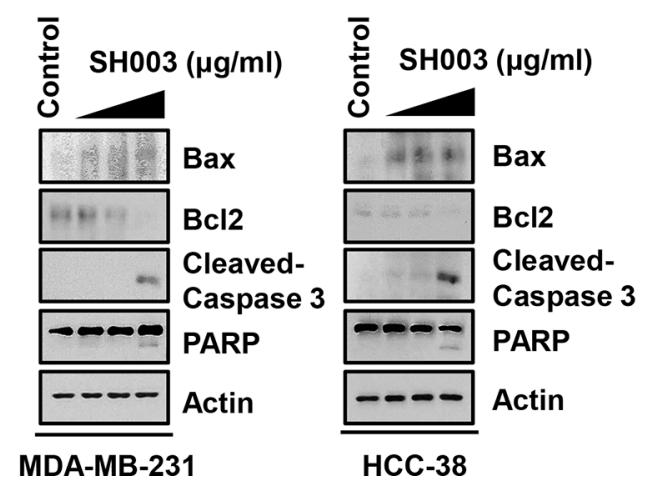

Figure 1: SH003 induces apoptotic cell death. (A) Cell viability was measured by MTT assay. MDA-MB-231 and HCC-38 cells were seed in 96-well plates and treated with various concentration of SH003 $(0,100,250$ and $500 \mu \mathrm{g} / \mathrm{ml})$ for 48 hours. Data were analyzed by ANOVA with $P<0.05$. (B) After MDA-MB-231 cells were treated with $500 \mu \mathrm{g} / \mathrm{ml}$ of SH003 for 48 hours, live and dead assay was done by using live and dead cell assay kit. Dead cells (Red fluorescence-positive cells) were counted. $* P<0.05$. (C) MDA-MB-231 and HCC-38 cells were treated with different doses of SH003 for 48 hours. Cells were stained with Annexin V and 7AAD at room temperature in the dark. Annexin V-positive apoptotic cells were detected using FACSCalibur. ${ }^{*} P<0.05$. Graph shows annexin V-positive apoptotic cells $(\%)$ calculated from the total amount of right-upper and -lower portion. (D) Cells were treated with $500 \mu \mathrm{g} / \mathrm{ml}$ of SH003 for 24 hours and then performed western blots with anti-Bax, -Bcl2, -Cleaved caspase 3 and PARP. Actin was used for the internal control. Experiments were performed in triplicate. Bars indicate means that standard deviations (SD). 
A

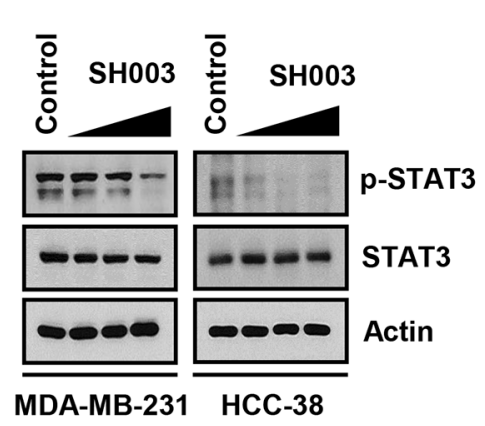

B

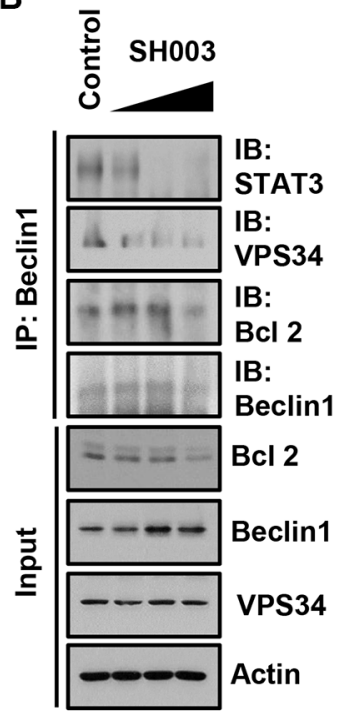

C

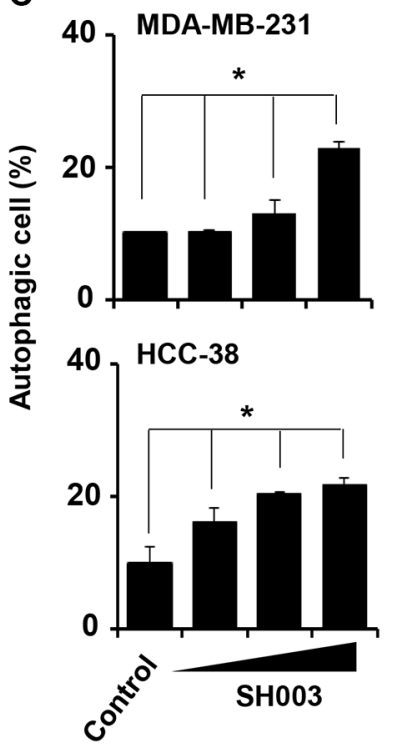

$\mathbf{E}$

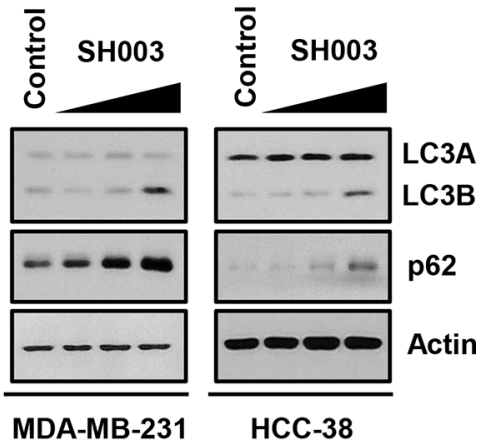

MDA-MB-231

HCC-38
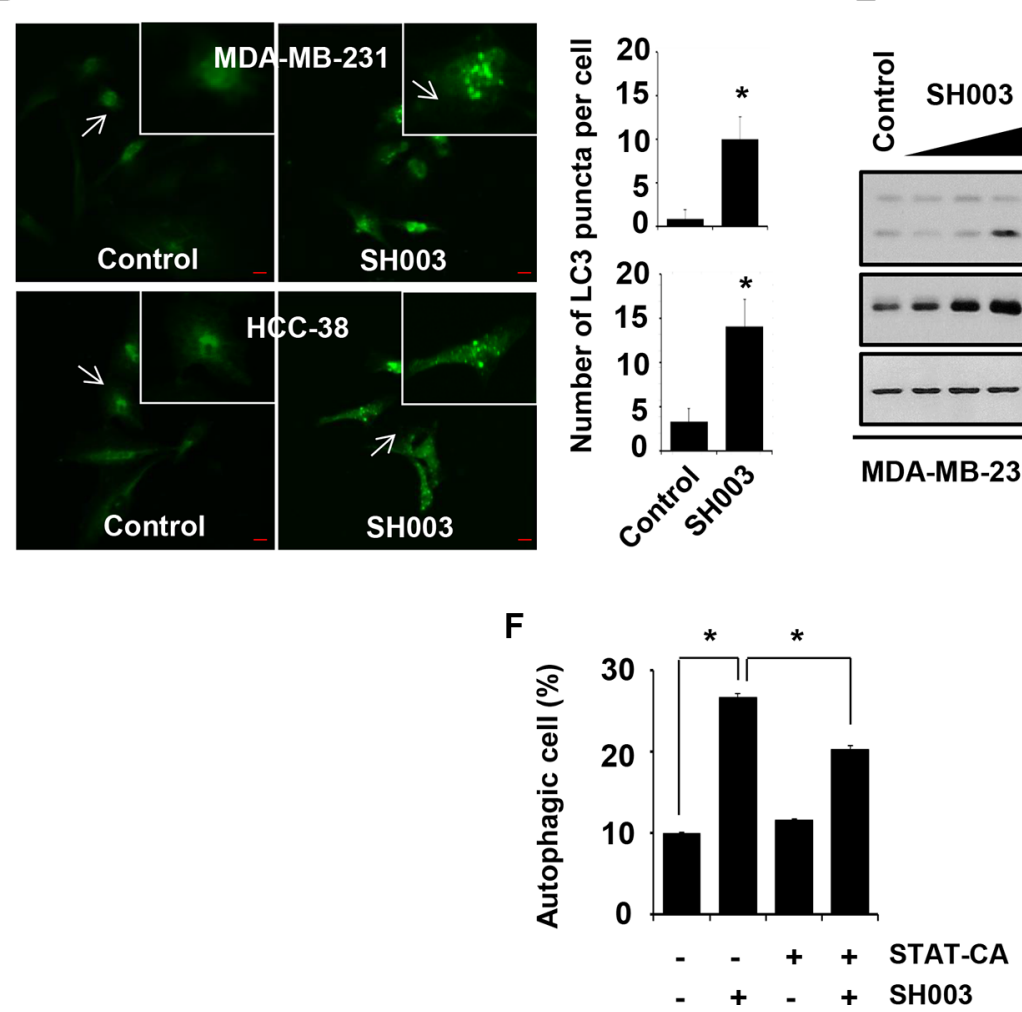

Figure 2: SH003 induces autophagy by suppressing STAT3 phosphorylation. (A) MDA-MB-231 and HCC-38 cells were treated with different doses of SH003 for 15 minutes and then performed western blots with anti-p-STAT3 and STAT3. Actin was used for the internal control. (B) Cells were treated with SH003 for 24 hours and whole-cell lysates were immunoprecipitated with anti-Beclin1 antibody. The immunoprecipitants and input proteins were then blotted with the antibodies for STAT3, VPS34, BCl-2, Beclin1 and actin. (C) MDA-MB-231 and HCC-38 cells were treated with SH003 (0, 100, 250 and $500 \mu \mathrm{g} / \mathrm{ml})$ for 24 hours and then stained with Cyto-ID fluorescence dye for 30 minutes at room temperature in the dark. Data analyzed using a FACSCalibur. Data were analyzed by ANOVA with $P<0.05$. (D) MDA-MB-231 and HCC-38 cells were treated with $500 \mu \mathrm{g} / \mathrm{ml}$ of SH003 for 24 hours and then stained with antiLC3B antibody $(1 \mu \mathrm{g} / \mathrm{ml})$ and anti-Alexa Fluor-488 (1:250) antibody. LC3 punctate in the cells were analyzed using Olympus FV10i Self Contained Confocal Laser System. The object was $20 \times$ and scale bar indicates $10 \mu \mathrm{m} .{ }^{*} P<0.05$. (E) Analysis of autophagy-related molecules. Cells were treated with SH003 for 24 hours and whole-cell lysates were analyzed by western blots with anti-LC3A/B and p62/SQSTM1. Actin was used for the loading control. (F) Cells were transfected with STAT3-CA and treated with SH003 for 24 hours. Autophagosome formation was stained with Cyto-ID fluorescence. ${ }^{*} P<0.05$. Experiments were performed in triplicate. Bars indicate means that standard deviations (SD). 
(lysosomal lumen alkalizer [36]), and then p62 level was analyzed using western blots and FACS. SH003 and autophagy inhibitors increased intracellular p62 level (Figure 5A and 5B), suggesting that $\mathrm{SH} 003$ accumulation of p62 level might reflect the inhibition of particular step in autophagy processes. Accordingly, those data support our hypothesis that $\mathrm{SH} 003$ might inhibit autolysosomal degradation of p62. Supportively, SH003 increased a number of cells where p62 co-localized with LAMP2, indicating that the accumulation of p62 in autolysosomes (Figure 5C). Lysosomal proteases like Cathepsins degrades p62 [1, 37]. SH003 reduced levels of both Cathepsin $\mathrm{B}$ and Cathepsin D (Figure 5D). Moreover, SH003 decreased levels of lysosomal Cathepsins (Figure 5E). Thus, those data indicate that $\mathrm{SH} 003$ accumulates p62 in autolysosomes by reducing Cathepsins.

A
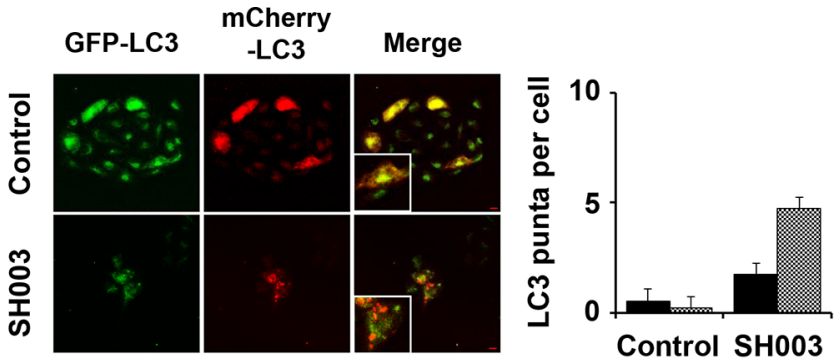

- Autophagosomal LC3

\& Autolysosomal LC3

B
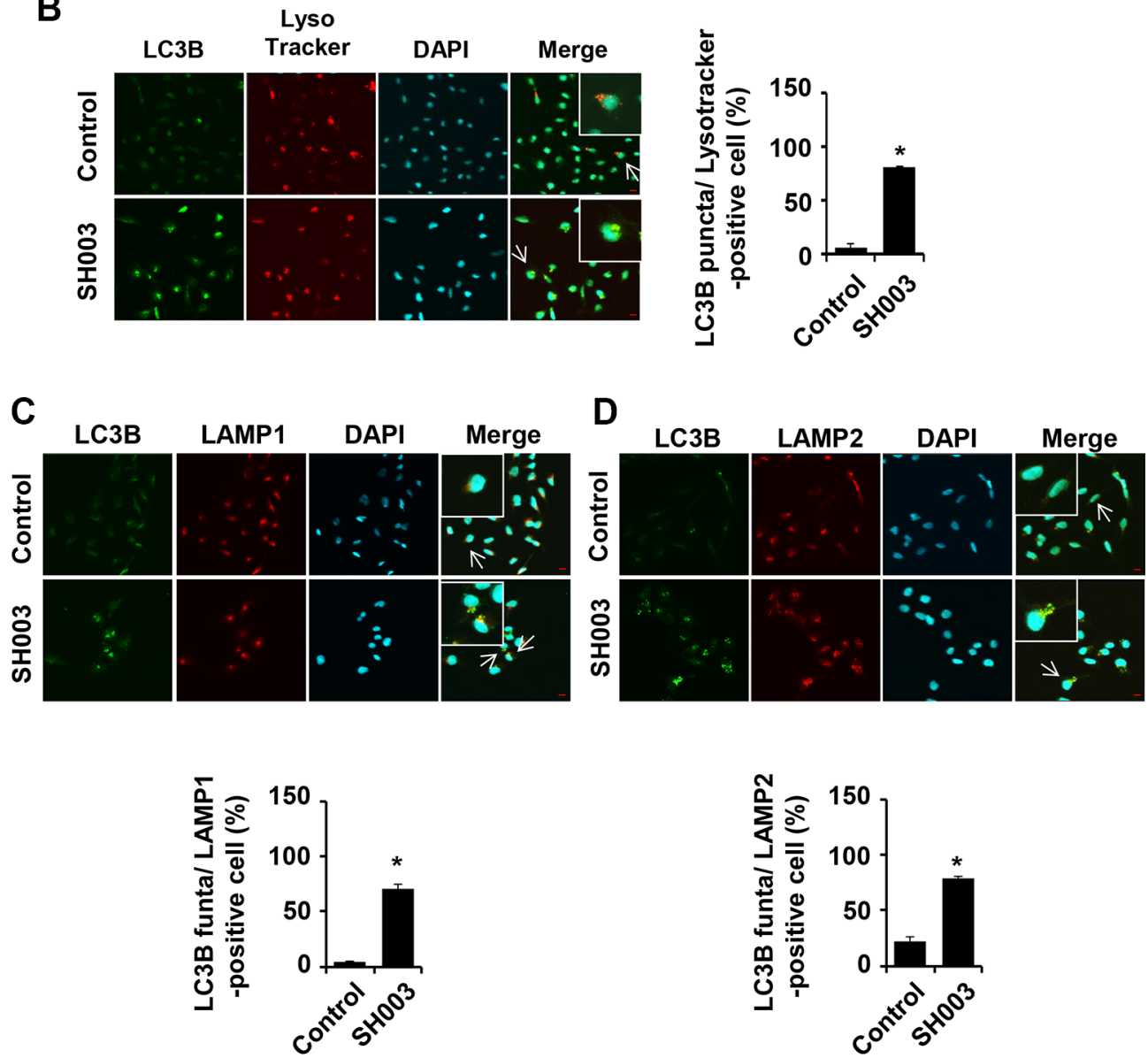

Figure 3: SH003 induces autolysosome formation. (A) Stable expression of mCherry-GFP-LC3 MDA-MB-231 cells were treated with $500 \mu \mathrm{g} / \mathrm{ml}$ of SH003 for 24 hours and images were obtained with using Olympus FV10i Self Contained Confocal Laser System. Yellow (double staining with GFP and RFP) and red (staining with only RFP) florescence were stained for autophagosome and autolysosome, respectively. The object was $20 \times$ and scale bar indicates $10 \mu \mathrm{m} .{ }^{*} P<0.05$. (B) MDA-MB-231 cells were treated with SH003 for 24 hours and stained with DND-99 lysotracker dye $(75 \mathrm{nM})$ for 1 hour at $37^{\circ} \mathrm{C}$. After fixation, permeabilization and blocking, cells were stained with anti-LC3B and Alexa-488 antibodies. DAPI was used for nucleus staining. (C) Cells were treated with SH003 for 24 hours and stained with anti-LC3B and LAMP1 (1:100) antibodies. (D) MDA-MB-231 cells were stained with anti-LC3B and LAMP2 (1:100) antibody. Colocalization with LC3B and LAMP2 was analyzed using Olympus FV10i Self Contained Confocal Laser System. The object was 20× and scale bar indicates $10 \mu \mathrm{m} .{ }^{*} P<0.05$. 
A

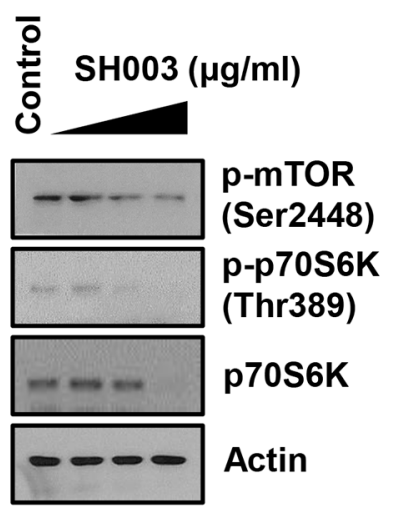

B

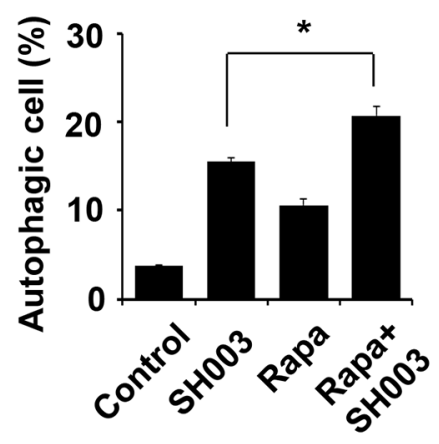

\section{C}
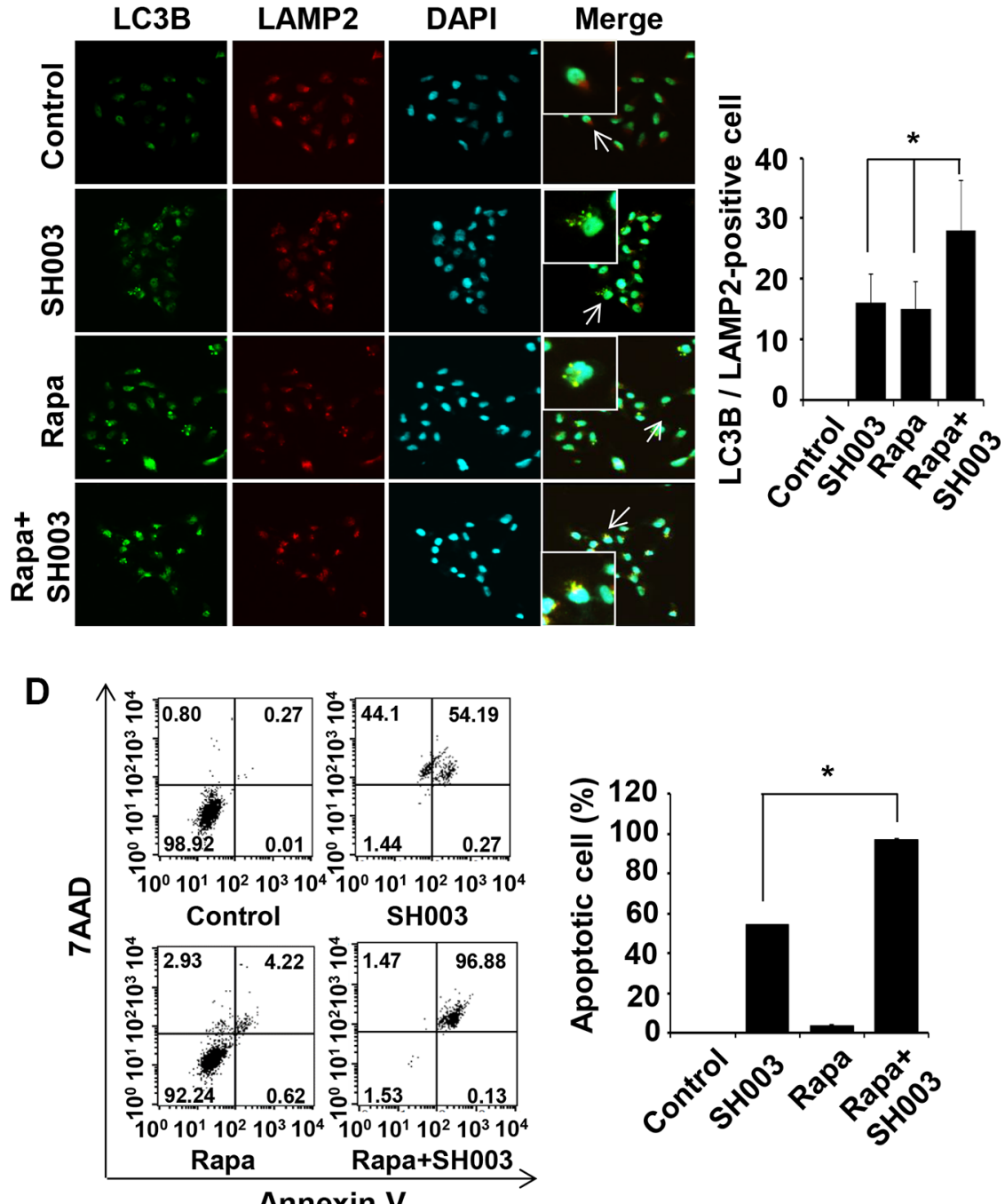

Figure 4: Rapamycin enhances SH003-induced autophagy-mediated apoptosis. (A) MDA-MB-231 cells were treated with different concentrations of SH003 $(0,100,250$ and $500 \mu \mathrm{g} / \mathrm{ml})$ for 24 hours and then subjected to western blots with the antibodies indicated (anti-p-mTOR, -p-p70S6K and -p70S6K). Actin was used as internal control. (B) Cells were treated with $10 \mu \mathrm{M}$ of rapamycin (Rapa) and $500 \mu \mathrm{g} / \mathrm{ml}$ of SH003 and then autophagosome vacuoles were measured by Cyto-ID fluorescence. Data analyzed using a FACSCalibur. ${ }^{*} P<0.05$. (C) MDA-MB-231 cells were treated with rapamycin and SH003 and then stained with anti-LC3B and LAMP2 antibodies. Colocalization with LC3B and LAMP2 were analyzed using Olympus FV10i Self Contained Confocal Laser System. The object was 20× and scale bar indicates $10 \mu \mathrm{m} . * P<0.05$. (D) Cells were treated with rapamycin and SH003 for 48 hours and then stained with Annexin V and 7AAD at room temperature in the dark. Annexin V-positive apoptotic cells were detected using FACSCalibur. ${ }^{*} P<0.05$. Representative data were presented as the means and standard deviations (SD). 
Meanwhile, although CQ also accumulated p62 level and induced autophagy, it failed to cause apoptosis (Figures 5A, 5B, 6A and 6B). Therefore, SH003-induced apoptosis might require more complex mechanisms that might not be induced by CQ. Moreover, we found that co-treatment of $\mathrm{SH} 003$ with $\mathrm{CQ}$ slightly increased cell numbers in autophagy and apoptosis, respectively (Figure 6A and 6B). We confirmed that co-treatment of SH003 with CQ increased PARP cleavage and LC3B production (Figure 6C). Therefore, our data suggested that they could synergize autophagy-induced apoptosis. Furthermore, p62 silencing reduced SH003-mediated
A

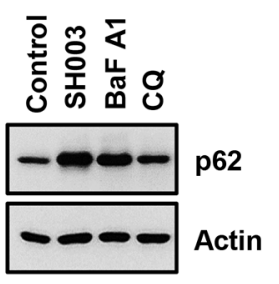

B

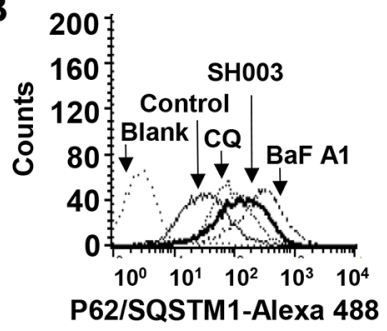

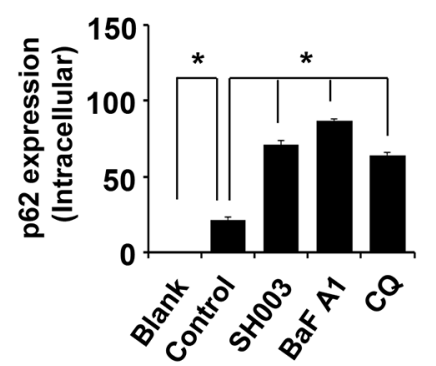

C

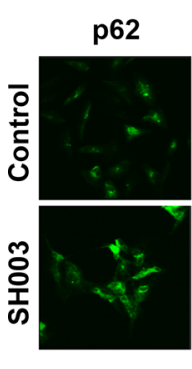

LAMP2

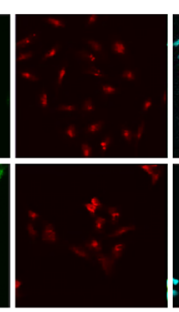

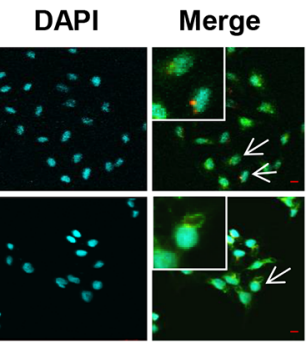

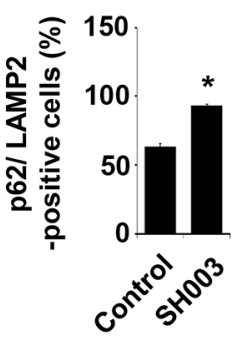

D

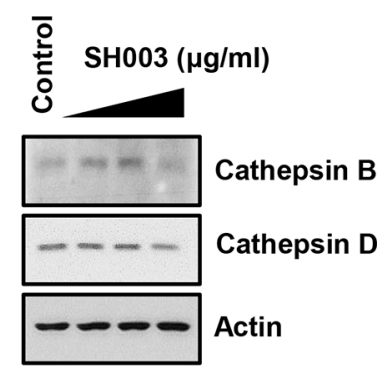

E
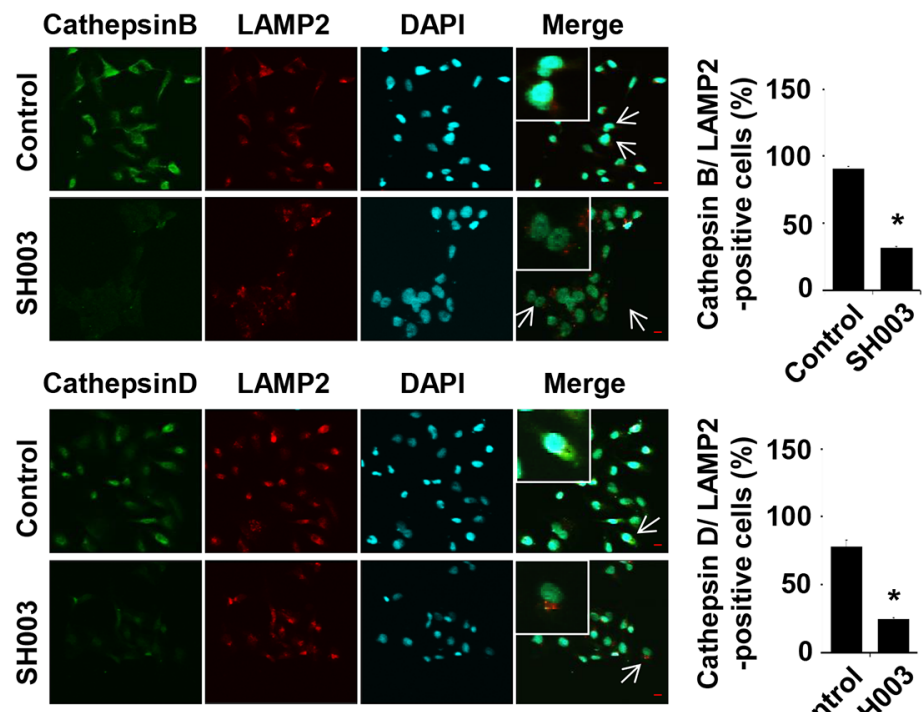

Figure 5: SH003 induces p62 accumulation via reduction of Cathepsin expression. (A) MDA-MB-231 cells were treated with SH003 $(500 \mu \mathrm{g} / \mathrm{ml})$, BaFA1 $(400 \mathrm{nM})$ and CQ $(10 \mu \mathrm{M})$ for 24 hours. p62 protein expression was objected with western blots. Actin was used for the internal control. (B) Cells were treated with SH003 and autophagy inhibitors (BaFA1 and CQ) for 24 hours and stained with p62 -Alexa 488-conjugated p62 antibody for 30 minutes. p62 accumulation in the cells were detected using FACSCalibur. ${ }^{*} P<0.05$. (C) MDA-MB-231 cells were treated with SH003 for 24 hours and stained with p62 $(1 \mu \mathrm{g} / \mathrm{ml})$ and LAMP2. DAPI was used as nucleus staining. The object was $20 \times$ and scale bar indicates $10 \mu \mathrm{m}$. ${ }^{*} P<0.05$. (D) Cells were treated with SH003 for 24 hours and then performed western blots with anti-Cathepsin B and -Cathepsin D. Actin was used for loading control. (E) MDA-MB-231 cells were treated with $500 \mu \mathrm{g} / \mathrm{ml}$ of SH003 for 24 hours and stained with Cathepsin B (1:50)/LAMP2 and Cathepsin D (1:50)/LAMP2. Images were obtained with using Olympys FV10i Self Contained Confocal Laser System. The object was $20 \times$ and scale bar indicates $10 \mu \mathrm{m} .{ }^{*} P<0.05$. Experiments were performed in triplicate. Bars indicate means that standard deviations (SD). 
apoptosis (Figure 6D and 6E), indicating that p62 might be prominent for $\mathrm{SH} 003$-induced apoptosis.

\section{SH003-induced p62 accumulation causes reactive oxygen species-mediated apoptosis}

p62 accumulation has been revealed to cause reactive oxygen species (ROS) generation[38-40]. In our study, SH003 increased ROS generation by approximately seven folds, and a well-known ROS scavenger, $\mathrm{N}$-acetyl-Lcysteine (NAC) inhibited $\mathrm{SH} 003$ effect on ROS generation (Figure 7A). Moreover, p62 silencing decreased SH003-induced ROS generation (Figure 7B), suggesting that p62 accumulation might be required for ROS generation. In additions, NAC reduced SH003mediated apoptosis (Figure 7C). Therefore, we draw that
A
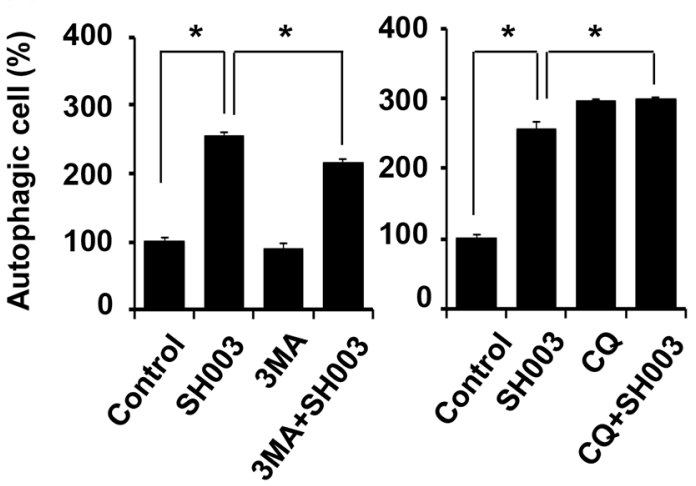

C

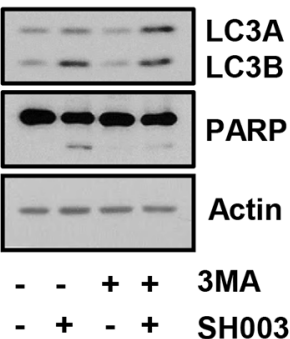

B
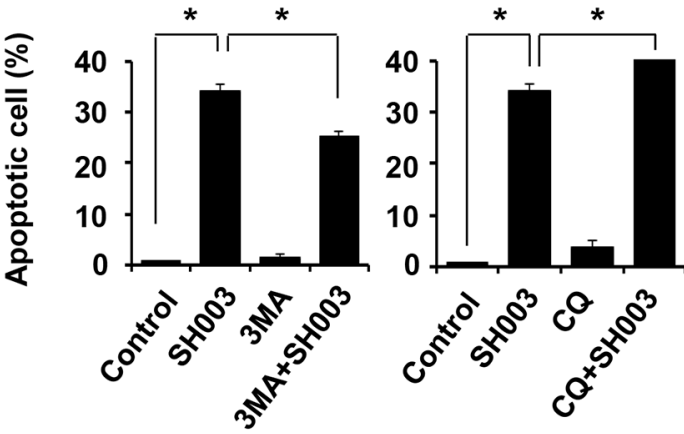

D
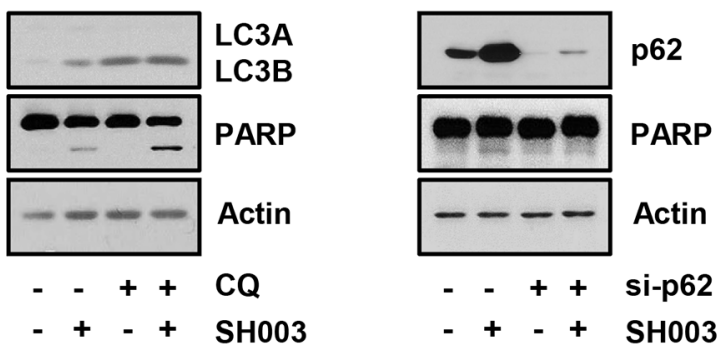

$\mathbf{E}$

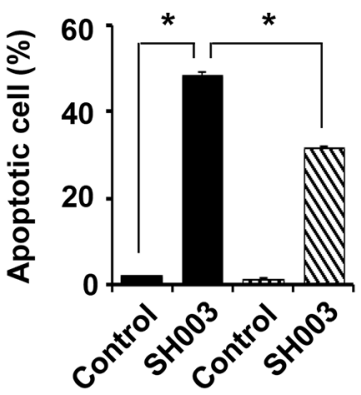

si Control si p62

Figure 6: SH003-induced p62 accumulation causes autophagy-mediated apoptosis. (A) MDA-MB-231 cells were pretreated with $1 \mathrm{mM}$ of $3 \mathrm{MA}$ and $10 \mu \mathrm{M}$ of CQ for 30 minutes and then treated with $500 \mu \mathrm{g} / \mathrm{ml}$ of SH003. After 24 hours, cells were stained with Cyto-ID fluorescence dye for 30 minutes and analyzed using a FACSCalibur. ${ }^{*} P<0.05$. (B) Cells were treated with SH003 for 24 hours and then stained with annexin V and 7AAD at room temperature in the dark. Autophagy inhibitors (3MA and CQ) were treated 30 minutes before SH003 treatment. Annexin V-positive apoptotic cells were detected using FACSCalibur. $* P<0.05$. (C) MDA-MB-231 cells were pretreated with 3MA and CQ for 30 minutes and then treated with SH003. 24 hours after treatment, LC3A/B, PARP and actin levels were examined. (D) MDA-MB-231 cells were transfected with p62 siRNA, treated with SH003 and performed western blots with anti-p62 and -PARP antibodies. Actin was used as internal controls. (E) Cells were transfected with control siRNA and p62 siRNA and then treated with $500 \mu \mathrm{g} / \mathrm{ml}$ of SH003. After 48 hours, cells were stained with Annexin V and 7AAD at room temperature in the dark. Annexin V-positive apoptotic cells were detected using FACSCalibur. ${ }^{*} P<0.05$. Experiments were performed in triplicate. Bars indicate means that standard deviations (SD). 
SH003-induced p62 accumulation causes ROS-mediated apoptosis.

\section{SH003 represses in vivo tumor growth}

To examine SH003 effect in vivo, we conducted the xenograft mouse tumor growth assay by orthotopically injecting MDA-MB-231 cells into nude mice. Mice were then orally administrated with different concentrations $(0$, 10,100 and $500 \mathrm{mg} / \mathrm{kg}$ ) of SH003 every day for 15 days. $\mathrm{SH} 003$ at $500 \mathrm{mg} / \mathrm{kg}$ strongly inhibited tumor growth with no effect on body weight (Figure 8A and 8B). In addition, our histology data showed that SH003 decreased Ki-67 and p-STAT3-positive cell numbers and increased the number of cells stained with cleavage Caspase-3, LC3B or p62 (Figure 8C). Thus, our in vivo study confirmed that
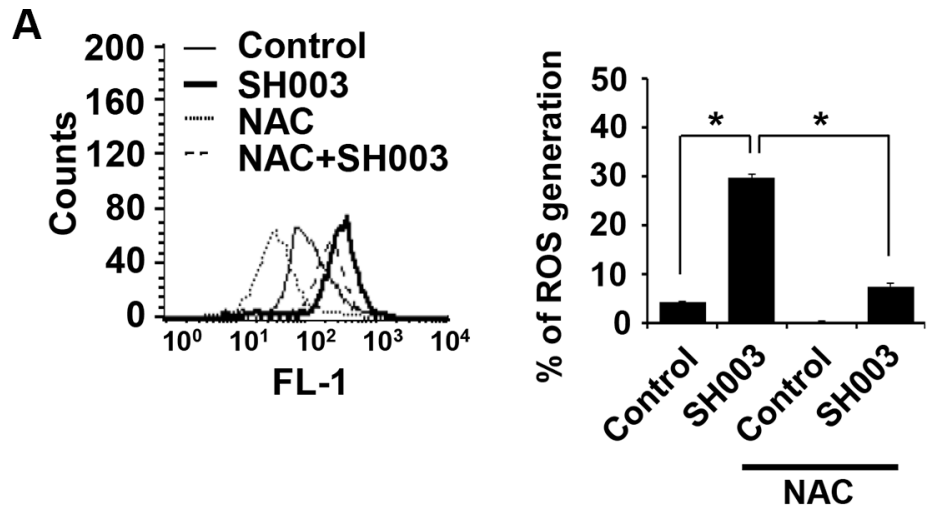

B
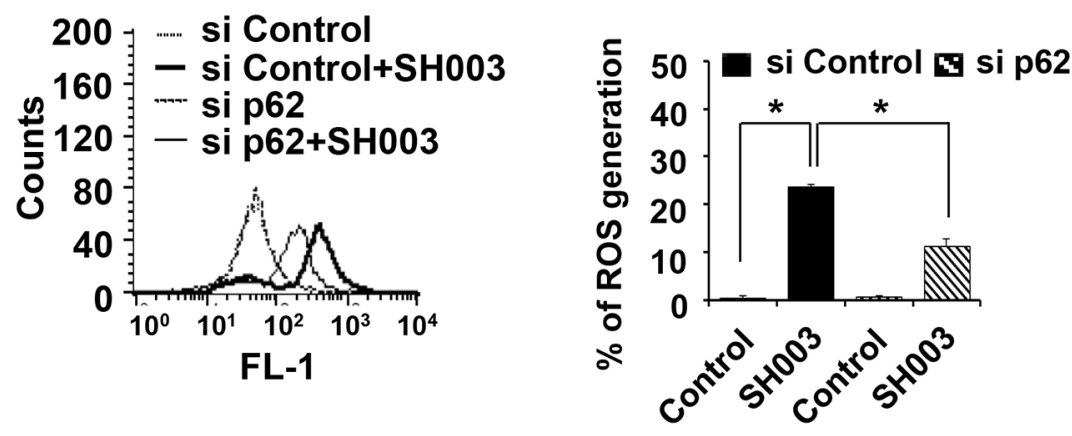

C
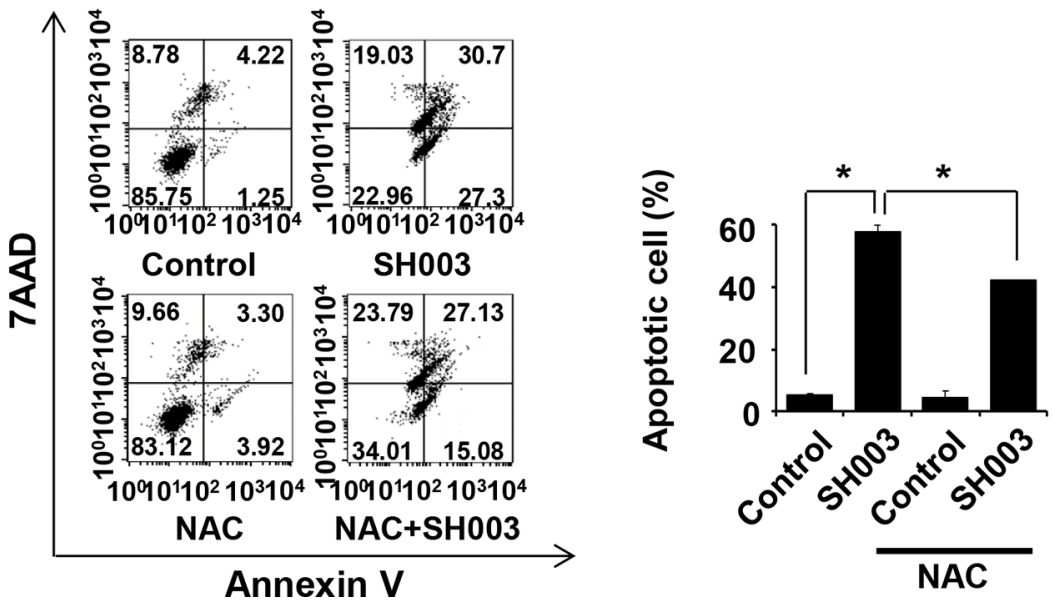

Figure 7: SH003-induced p62 accumulation causes ROS-mediated apoptotic cell death. (A) MDA-MB-231 cells were pretreated with or without NAC $(2.5 \mathrm{mM})$ for 1 hour, followed by exposure to SH003. After 24 hours, cells were stained with $\mathrm{H}_{2} \mathrm{DCFDA}$ for 1 hour at $37^{\circ} \mathrm{C}$. ROS generation was detected with using FACSCalibur by the FL1 channel. (B) Cells were transfected with control siRNA and p62 siRNA and then treated with SH003 for 24 hours. ROS generation was measured by FACSCalibur. ${ }^{*} P<0.05$. (C) Cells were pretreated with NAC for 1 hour and then treated with $500 \mu \mathrm{g} / \mathrm{ml}$ of SH003 for 48 hours. Cells were stained with annexin V and 7AAD. $* P<0.05$. Experiments were performed in triplicate. Bars indicate means that standard deviations (SD). 
SH003 suppresses tumor growth by inducing autophagymediated apoptosis.

\section{SH003 toxicity}

We SH003 toxicity tests in Sprague-Dawley (SD) rats. To test an acute toxicity, the animals were divided into 4 groups: a vehicle control group and SH003administrated groups (500, 1000 and $2000 \mathrm{mg} / \mathrm{kg}$ ), each group was consisted of 5 rats of each sex. The rats were orally administrated with distilled water (vehicle group) or SH003. Fourteen days after oral administration, body weight, mortality, clinical signs and gross findings were recorded (Figure S1 and Table S1). Thus our acute toxicity data suggest that the lethal dose was more than $2000 \mathrm{mg} / \mathrm{kg}$ for both genders. For four-week-repeated oral dose toxicity study, animals were orally administrated with SH003 at different doses $(0,500,1000$ and $2000 \mathrm{mg} / \mathrm{kg}$ ) every day for 4 weeks. SH003 did not result in any toxicological changes, such as mortality, common symptom, body weight, food intake, hematological values, serum biochemical values, relative organ weights, clinical signs and histopathology (Figure S2 and Table S2). Considering our toxicity studies, the no-observed-adverseeffect level (NOAEL) was determined higher than 2000 $\mathrm{mg} / \mathrm{kg}$ for both male and female animals. In thirteen-
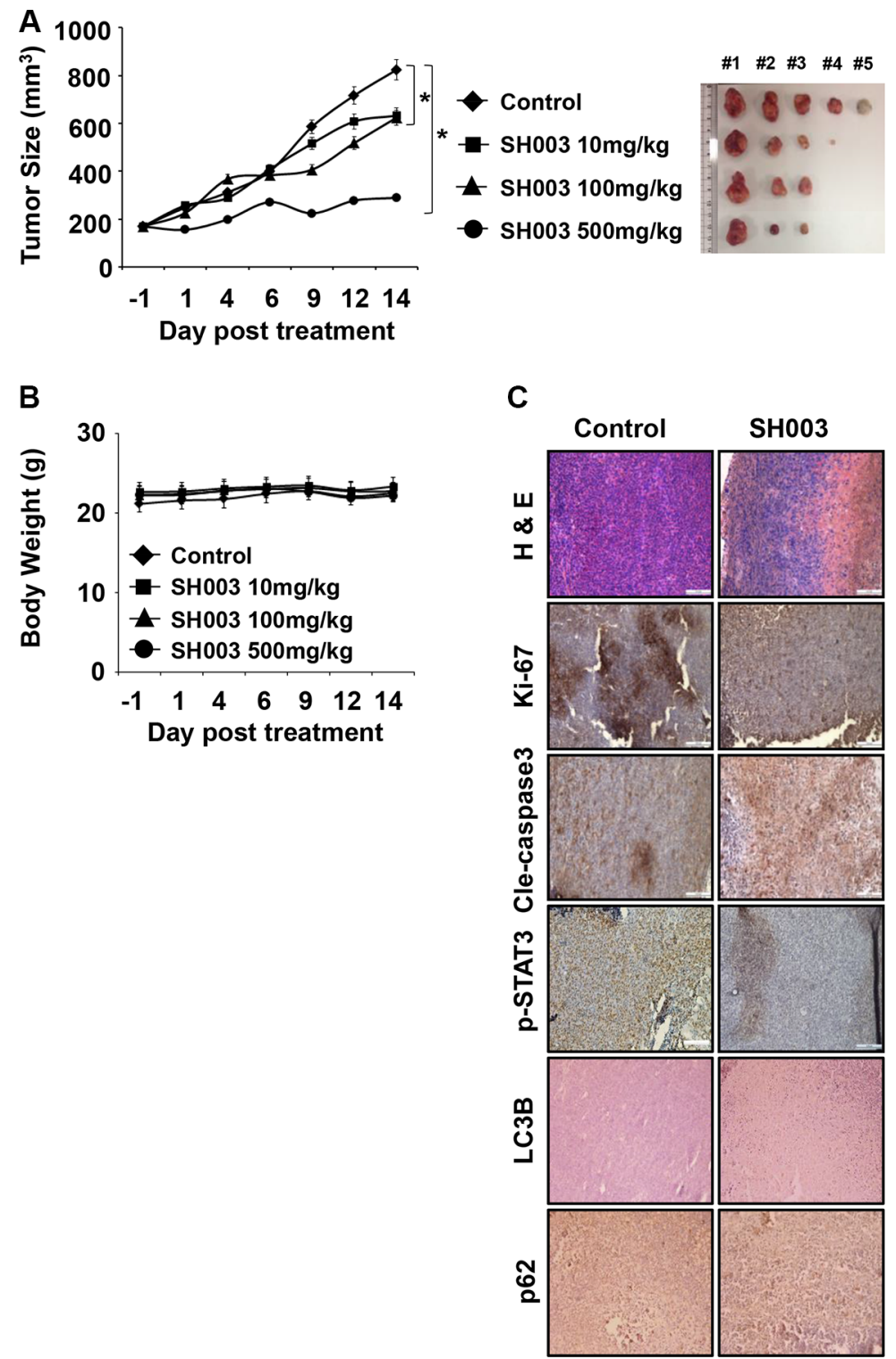

Figure 8: SH003 suppresses in vivo tumor growth. (A) $5 \times 10^{5}$ MDA-MB-231 cells were s.c. injected and mice $(n=5 /$ group) were p.o. administrated daily with different concentrations of SH003 (10, 100 and $500 \mathrm{mg} / \mathrm{kg})$ for 15 days. Xenograft tumor volumes and body weight of mice were measured three times a week. Tumor volumes were calculated using the following: Tumor volume (cubic millimeters) $=$ width $^{2} \times$ length $/ 2$. Data were analyzed by ANOVA with $P<0.05$. (B) Body weight $(\mathbf{C})$ Tumor tissues were stained with hematoxylin, eosin and antibodies indicated (anti-Ki-67, -Cleaved caspase 3, -p-STAT3, -LC3B and -p62). Images were obtained at 20× magnification. The scale bar indicates $100 \mu \mathrm{m}$. Bars indicate means that standard deviations (SD). 
week-repeated oral dose toxicity test, male and female rats were randomly assigned to four groups: control $(n=15)$, low $(625 \mathrm{mg} / \mathrm{kg} \mathrm{SH003,} n=10)$, medium $(1250 \mathrm{mg} / \mathrm{kg}, n=10)$ and high $(2500 \mathrm{mg} / \mathrm{kg}, n=15)$ groups. The rats were orally administrated with distilled water (vehicle group) or SH003 every day. Thirteen weeks after administrations, we allocated five of both male and female rats from the control and $2500 \mathrm{mg} / \mathrm{kg}$ SH003-treated group, respectively, and observed those animals for another four weeks. SH003 resulted in no significant differences in body weight changes, food consumptions, ophthalmoscopy findings, urinalysis, hematological values, serum biochemical values, blood coagulation values, absolute organ weights and clinical signs. In additions, hypertrophy of liver was observed in the 13-week repeated toxicity test, but this symptom was not observed during the 4-week recovery period (Figure S3 and Table S3). Thus our 13-week repeated-with a 4 weeks recovery period data demonstrated that NOAEL was more than $2500 \mathrm{mg} / \mathrm{kg}$ for both genders.

\section{SH003 component profiling and mechanism action}

Components in SH003 were analyzed using high performance liquid chromatography (HPLC), and characterized in terms of both retention time and UV spectrum. This analysis confirmed twenty components (tryptophan: tR $2.93 \mathrm{~min}$, umbeliferone: tR $3.20 \mathrm{~min}$, chlorogenic acid: tR $3.76 \mathrm{~min}, 3-\mathrm{O}$-feruloylquinic acid: tR 7.20 min, calycosin-7-O- $\beta$-D-glucoside: tR $8.44 \mathrm{~min}$, nodakenin isomer: tR $9.01 \mathrm{~min}$, nodakenin: $\mathrm{tR} 9.08 \mathrm{~min}$, marmesin / 7-hydroxy-6-(2R)-hydroxy-3-methylbut-3ethyl)coumarin: tR $10.17 \mathrm{~min}$, marmesin / 7-hydroxy-6(2R)-hydroxy-3-methylbut-3-ethyl)coumarin: tR 11.21 min, decursinol: tR $11.75 \mathrm{~min}$, calycosin: tR 12.04 min, bergapten(5-methoxypsoralen) : tR $13.79 \mathrm{~min}$, isopimpinellin: tR $14.90 \mathrm{~min}$, formononetin: tR 15.05 min, (6aR, 11aR)-3-hydroxy-9,10-dimethoxypterocarpa: tR 15.47 min, osthenol: tR $17.60 \mathrm{~min}$, decursin: tR 20.40 min, decursinol angelate : tR 20.57 min and two-unknown: tR $1.59 \mathrm{~min}$ and $20.85 \mathrm{~min}$ ). In addition, one peak at 11.1 minutes (formononetin-7-O- $\beta$-D-glucoside) was not detected in SH003, while being found in Am (Figure S4 and S5). We recently confirmed SH003-contained components, such as formononectin, decursin, nodakenin and curcubitacin D [21]. Therefore, we further examined whether effects of these compounds were similar to those of SH003 in cancer cells. Cucurbitacin D showed similar effects to SH003 on autophagy and apoptotic cell death, while formononectin, decursin and nodakenin did not. Therefore, cucurbitacin D might be one of effective components of SH003 (Figure S6).

\section{Herb-drug interaction}

We further evaluated CYP450-mediated dug metabolism to test herb-drug interactions. Human liver microsomes were preincubated with different doses of $\mathrm{SH} 003(1,3,10,30,100$ and $300 \mu \mathrm{g} / \mathrm{ml})$, and then added with the substrates (40 $\mu \mathrm{m}$ of phenacetin, $2.5 \mu \mathrm{m}$ of coumarin, $10 \mu \mathrm{m}$ of paclitaxel, $10 \mu \mathrm{m}$ of diclofenac, $160 \mu \mathrm{m}$ of $( \pm)$-mephenytoin, $5 \mu \mathrm{m}$ of dextromethorphan and $2.5 \mu \mathrm{m}$ midazolam). SH003 had minimal inhibitory effects on all CYP isozymes and its IC50 was considered higher than $300 \mu \mathrm{g} / \mathrm{ml}$, although it reduced CYP1A2 enzyme activity with no significance (Table S4).

\section{DISCUSSION}

Our previous reports have shown that SH003 compared to each herbal component extract (Am, Ag and $\mathrm{Tk}$ ) inhibited tumor growth and metastasis on highly metastatic MDA-MB-231 breast cancer cells, both in vivo and in vitro without toxicity [21]. Moreover, SH003 regulation of STAT3 signaling was crucial for the inhibition of cancer growth and metastasis. We confirmed SH003 inhibition of tumor growth by repressing STAT3 activation. As $\mathrm{SH} 003$ caused apoptotic cell deaths of both MDA-MB-231 and HCC-38 breast cancer cells, it is convincing that $\mathrm{SH} 003$ could treat highly metastatic breast cancer. In molecular and cellular mechanisms, SH003 altered STAT3 interaction with Beclin1/VPS34/ Bcl2 complexes. Moreover, sustained STAT3 activation reduced SH003 induction of autophagy. Autophagy induction requires STAT3 interaction with Beclin1/VPS34/ Bcl2 complexes. Thus, SH003 regulation of STAT3 activation and complex formation would be crucial for the induction of autophagy and cancer treatment. In addition, we found that SH003 inhibited the activation of mTOR signaling in the induction of autophagy, which is consistent with recent studies that showed the inhibition of mTORSTAT3 in autophagy induction [41, 42]. Our data further suggest that mTOR and STAT3 might regulate autophagy in two different ways, as $\mathrm{SH} 003$ and rapamycin showed synergistic effect in autophagy induction. While we know mTOR and STAT3 regulate autophagy in the same autophagy signaling circuit [43-45], it is unclear whether and how mTOR and STAT3 independently works in autophagy induction. Thus, we need more basic knowledge to understand autophagy in treatment of cancer disease.

We further found that SH003 induction of autophagy increased p62 level, although autophagy has been known to reduce p62 level [32, 46]. Furthermore, SH003 reduced protein levels of Cathepsins, while it increased autolysosome numbers. SH003 induction of autophagy disrupts p62 degradation, resulting in apoptotic cell death via altering intracellular ROS level. Therefore, our data suggest that SH003 inhibition of p62 degradation in autolysosome causes ROS-mediated apoptotic cell death (Figure 9). Recent studies revealed that STAT3 regulates gene expression of Cathepsins [47]. Thus, SH003 inhibition of mTOR-STAT3 appears to increase p62 level by downregulating expression of Cathepsins. 
Our study shows that SH003 inhibits cancer growth both in vitro and in vivo systems via inductions of autophagymediated apoptosis. Moreover, studies using herbal medicine reveal one of biological mechanisms of autophagy-mediated apoptosis. However, it is still unclear which chemical components directly affect mTOR and/or STAT3. Therefore, our ongoing studies hope to decipher how chemical components of SH003 work biochemically in the cells. Meanwhile, toxicity studies with GLP regulations conclude that $\mathrm{SH} 003$ is safe in rats. Thus, our future clinical studies will answer whether SH003 can be used to treat cancer with safety.

\section{MATERIALS AND METHODS}

\section{Chemicals and reagents}

Cyto-ID autophagy detection kit was obtained from Enzo Life Sciences (Villeurbanne, France). Live and dead cell assay kit was purchased from Abcam (Cambridge, UK). 3-(4,5-dimethylthiazol-2-yl)-2,5diphenyl-tetrazolium bromide (MTT), bafilomycin A1 (BaF A1), chloroquine (CQ), 3-methyladenine (3-MA) formononectin, decursin and $\mathrm{N}$-acetyl-L-cysteine (NAC) were from Sigma-Aldrich (St. Louis, MO, USA). Alexa fluor-488, Alexa fluor-594 and Lipofectamine reagent were obtained from Invitrogen (Garlsbad, CA, USA). Protein A/G plusagarose beads and p62 siRNA were purchased cell signaling (Danvers, MA, USA). pBABE-puromCherry-EGFP-LC3B (addgene 22418) and EF.STAT3C.Ubc.GFP (addgene 24983) were from addgene (Cambridge, MA, USA). Nodakenin was purchased from ChemFaces (Wuhan, China) and cucurbitacin D was obtained from Extrasynthese (Genay, France).

\section{Preparation of SH003 and HPLC analysis}

SH003 extract was provide from Hanpoong Pharm and Foods Company (Jeonju, Republic of Korea) manufactured by the Good Manufacturing Product (GMP). Extraction procedures were reported in previous study [21].

\section{Cell line and cell culture}

Human MDA-MB-231 cells were provided from American Type Culture Collection (Rockville, Maryland). The HCC-38 cells were obtained from the Korean Cell Line Bank (Seoul, South Korea). MDA-MB-231 cells were grown in DMEM medium containing 10\% FBS and antibiotics. HCC-38 cells were cultured in RPMI-1640 medium with $10 \%$ fetal bovine serum (FBS) $1 \%$ antibiotics.

\section{Cell viability and apoptotic analysis}

Cells were seed in 96-well plates and treated with different doses of $\mathrm{SH003}$ for 48 hours. Cell viability was determined using the MTT assay and absorbance was read at $570 \mathrm{~nm}$ on the ELISA reader (Molecular Devices, Palo Alto, CA, USA). Cells were seed in $60 \mathrm{~mm}$ dishes and treated with SH003 for 48 hours. Cells were harvested, resuspended in binding buffer and stained with Annexin V-FITC and 7-AAD in the dark at room temperature for 15 minutes. Annexin-positive apoptotic cells were measured by FACScalibur (BD Biosciences, San Jose, CA, USA). Live and dead assay was performed with the live and dead cell assay kit according to the manufacturer's instruction.

\section{Western blot and measurement of intracellular p62 by flow cytometry}

Cells were seed in 6-well plates and treated with different doses of SH003 for 24 hours. Cells were lyzed with RIPA buffer and equal amount of protein $(15 \mu \mathrm{g})$ in total cell extracts was separated by SDS-PAGE. After transferring to PVDF membrane, the membrane was blocked and blotted with the relevant primary antibodies. Anti-Bax, $-\mathrm{Bcl} 2$, -LC3A/B, Cathepsin B, Cathepsin D and -actin antibodies were purchased from Santa Cruz Biotechnology (Santa Cruz, CA, USA). Anti-cleaved caspase-3, -PARP, -p-mTOR, -p-p70S6K and -p70S6K antibodies purchased from Cell Signaling (Danvers, MA, USA). Anti-LC3B and

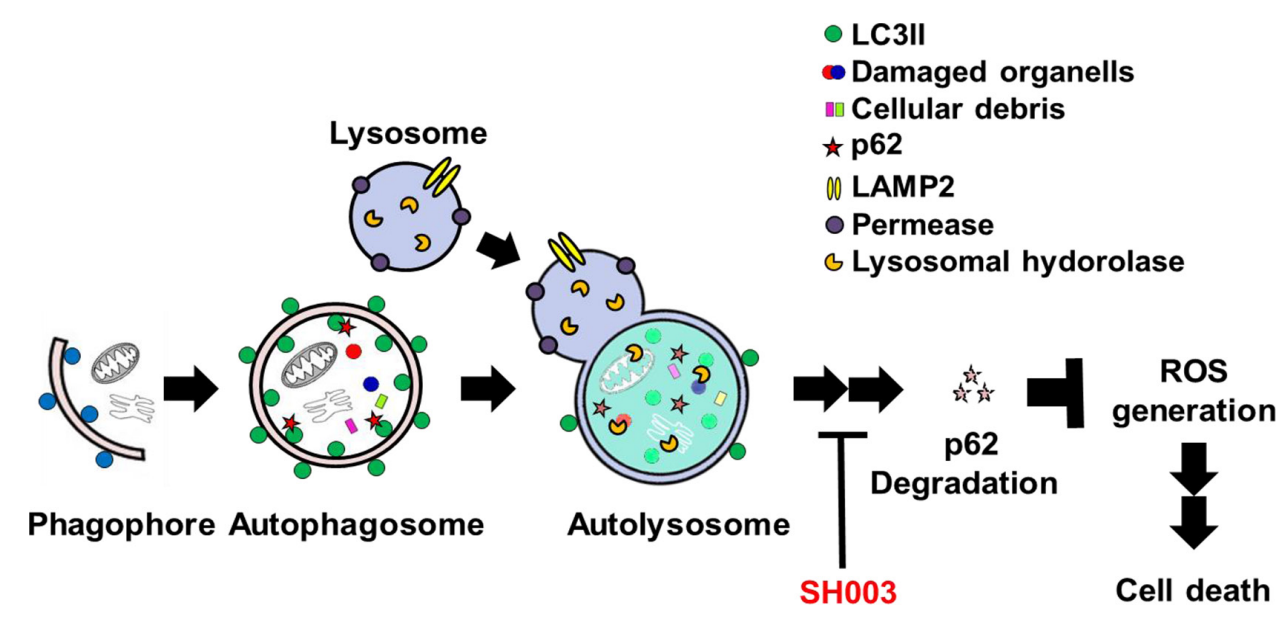

Figure 9: A schematic representation of the mechanisms for SH003 suppression of breast cancer growth. 
-p62 antibodies were purchased from Abcam (Cambridge, UK). Analysis of intracellular p62 expression was by flow cytometry using the Alexa Fluor 488-conjugated p62 antibody (BD Biosciences, San Jose CA, USA). Cells were seed in 6-well plates and then treated with $500 \mu \mathrm{g} /$ $\mathrm{ml}$ of SH003 and autophagy inhibitors, such as BaF1 and CQ for 24 hours. After permeabilized with $0.5 \%$ Tween-20 in $95 \%$ ethanol for 10 minutes, stained with Alexa Fluor 488-conjugated p62 antibody (1:50) for 30 minutes in dark. The data was analyzed by FACSCalibur flow cytometry measuring the green signal by the FL1 channel.

\section{Cyto-ID autophagy detection assay and ROS measurement}

Cyto-ID autophagy detection kit measures autophagic vacuoles by flow cytometry. Cells were seed in 6-well plates and treated with different doses of SH003 for 24 hours and stained with Cyto-ID green dye ( $1 \mu \mathrm{l} / 4 \mathrm{ml}$ assay buffer) for 30 minutes in dark. The data was analyzed by FACSCalibur flow cytometry measuring the green signal by the FL1 channel. For ROS generation, cells were seed in 6-well plates and pretreated with NAC ( $2.5 \mathrm{mM})$ for 1 hour before SH003 treatment. After 24 hours, cells were stained with $\mathrm{H}_{2}$ DCFDA for 1 hour at $37^{\circ} \mathrm{C}$ and analyzed by FACSCalibur flow cytometry measuring by the FL1 channel.

\section{Confocal microscopy}

For LC3B puncta formation, cells were seed in 6-well plates with coverglasses and treated with $\mathrm{SH} 003$ for 24 hours. Cells were stained with anti-LC3B antibody $(1 \mu \mathrm{g} / \mathrm{ml})$ and anti-Alexa Fluor-488 (1:250) antibody. For acidic organelles labeling, cells were incubated with lysotracker dye (Lysotracker Red DND-99, $75 \mathrm{nM}$ ) for 1 hour at $37^{\circ} \mathrm{C}$ and then stained with anti-LC3B antibody. For LAMP2 with p62 and Cathepsins staining, cells were stained with $1 \mu \mathrm{g} / \mathrm{ml}$ of LC3B, 1:100 of LAMP-1 and LAMP-2. Finally for p62/SQSTM1, Cathepsin B/LAMP2 and CathepsinD/LAMP2 staining, cells were stained with $1 \mu \mathrm{g} / \mathrm{ml}$ of p62, 1:100 of Cathepsin B, Cathepsin D and LAMP2. For the counter staining, DAPI was used to stain the nucleus. Images were acquired with Olympus FV10i Self Contained Confocal Laser System.

\section{Transfection}

In autophagosome, because LC3B is located on the membraines of autophagosome, GFP and mCherry colocalize and which can be visualized as a yellow pucta. In additions, only red signal is observed in autolysosome because mCherry retains its signal in the acidic $\mathrm{pH}$ but GFP signal is declined [48]. For mCherry-GFP-LC3 detection, expression vectors were transfected into cells by using Lipofectamine reagent. One day after transfection, transfected-cells were selected by using puromycin for
14 days. Stable expression of mCherry-GFP-LC3 cells were seed and treated with SH003 for 24 hours. Images were acquired with Olympus FV10i Self Contained Confocal Laser System. For p62 transient knockdown, cells were seed in 6-well plates and transfected with control and p62 siRNA using Lipofectamine reagent, followed by the Annexin $\mathrm{V}$ apoptosis analysis, western blot and ROS generation.

\section{In vivo studies}

Animal studies were approved by Kyung Hee University Institutional Animal Care and Use Committee (KHU-IACUC). Six-week-old nude $(\mathrm{Nu} / \mathrm{Nu})$ mice were obtained from Orient Bio (Seongnam, Korea). Mice were injected s.c with $5 \times 10^{5} \mathrm{MDA}-\mathrm{MB}-231$ cells and different dose of SH003 were p.o administrated daily for 15 days. Body weights and tumor volumes were monitored three times a week. Especially, tumor volumes were measured using caliper and calculated (width ${ }^{2} \times$ length/2). For immunohistochemistry, tumors were removed and fixed with $4 \%$ formaldehyde. Tumor tissues were embedded, dissected, diparaffinized and stained with Ki-67, Clecasplase-3, p-STAT3, LC3B and p62. Images were obtained with bright field microscope. The object was $20 \times$ and the scale bar on the image $(100 \mu \mathrm{m})$.

\section{Statistics}

All the data were performed in triplicate, and shown as means and standard deviations (SD). Data analyzed by Student's $t$-test or one-way ANOVA.

\section{CONFLICTS OF INTEREST}

The authors declare that they no conflicts interests.

\section{GRANT SUPPORT}

This research was supported by the Kyung Hee University in 2013, by Korea National University of Transportation in 2016, by Basic Science Research Program through the National Research Foundation of Korea (NRF) funded by the Ministry of Science, ICT \& Future Planning (NRF-2014R1A1A1035831), by Basic Science Research Program through the National Research Foundation of Korea (NRF) funded by the Ministry of Education, Science and Technology (20110022382), and by a grant from Korean Medicine R\&D project of the Ministry of Health and Welfare (B110043).

\section{Authors' contributions}

Youn Kyung Choi and Sung-Gook Cho contributed equally to this work. 


\section{REFERENCES}

1. Puissant A, Fenouille N, Auberger P. When autophagy meets cancer through p62/SQSTM1. Am J Cancer Res. 2012; 2:397-413.

2. Codogno P, Meijer AJ. Autophagy and signaling: their role in cell survival and cell death. Cell Death Differ. 2005; 12:1509-1518.

3. Mijaljica D, Prescott M, Klionsky DJ, Devenish RJ. Autophagy and vacuole homeostasis: a case for selfdegradation? Autophagy. 2007; 3:417-421.

4. Amaravadi RK, Lippincott-Schwartz J, Yin XM, Weiss WA, Takebe N, Timmer W, DiPaola RS, Lotze MT, White E. Principles and current strategies for targeting autophagy for cancer treatment. Clin Cancer Res. 2011; 17:654-666.

5. Ryter SW, Lee SJ, Smith A, Choi AM. Autophagy in vascular disease. Proc Am Thorac Soc. 2010; 7:40-47.

6. Singh R, Kaushik S, Wang Y, Xiang Y, Novak I, Komatsu M, Tanaka K, Cuervo AM, Czaja MJ. Autophagy regulates lipid metabolism. Nature. 2009; 458:1131-1135.

7. Xie M, Morales CR, Lavandero S, Hill JA. Tuning flux: autophagy as a target of heart disease therapy. Curr Opin Cardiol. 2011; 26:216-222.

8. Bonaldo P, Sandri M. Cellular and molecular mechanisms of muscle atrophy. Dis Model Mech. 2013; 6:25-39.

9. Nixon RA. The role of autophagy in neurodegenerative disease. Nat Med. 2013; 19:983-997.

10. Schneider JL, Cuervo AM. Liver autophagy: much more than just taking out the trash. Nat Rev Gastroenterol Hepatol. 2014; 11:187-200.

11. Cadwell K, Liu JY, Brown SL, Miyoshi H, Loh J, Lennerz JK, Kishi C, Kc W, Carrero JA, Hunt S, Stone CD, Brunt EM, Xavier RJ, et al. A key role for autophagy and the autophagy gene Atg1611 in mouse and human intestinal Paneth cells. Nature. 2008; 456:259-263.

12. Mathew R, White E. Autophagy in tumorigenesis and energy metabolism: friend by day, foe by night. Curr Opin Genet Dev. 2011; 21:113-119.

13. Yang ZJ, Chee CE, Huang S, Sinicrope FA. The role of autophagy in cancer: therapeutic implications. Mol Cancer Ther. 2011; 10:1533-1541.

14. Fung C, Lock R, Gao S, Salas E, Debnath J. Induction of autophagy during extracellular matrix detachment promotes cell survival. Mol Biol Cell. 2008; 19:797-806.

15. Martinet W, Agostinis P, Vanhoecke B, Dewaele M, De Meyer GR. Autophagy in disease: a double-edged sword with therapeutic potential. Clin Sci. 2009; 116:697-712.

16. Degenhardt $\mathrm{K}$, Mathew $\mathrm{R}$, Beaudoin $\mathrm{B}$, Bray $\mathrm{K}$, Anderson D, Chen G, Mukherjee C, Shi Y, Gelinas C, Fan Y, Nelson DA, Jin S, White E. Autophagy promotes tumor cell survival and restricts necrosis, inflammation, and tumorigenesis. Cancer Cell. 2006; 10:51-64.
17. Amaravadi RK, Yu D, Lum JJ, Bui T, Christophorou MA, Evan GI, Thomas-Tikhonenko A, Thompson CB. Autophagy inhibition enhances therapy-induced apoptosis in a Myc-induced model of lymphoma. J Clin Invest. 2007; 117:326-336.

18. Longo L, Platini F, Scardino A, Alabiso O, Vasapollo G, Tessitore L. Autophagy inhibition enhances anthocyanininduced apoptosis in hepatocellular carcinoma. Mol Cancer Ther. 2008; 7:2476-2485.

19. Verschooten L, Barrette K, Van Kelst S, Rubio Romero N, Proby C, De Vos R, Agostinis P, Garmyn M. Autophagy inhibitor chloroquine enhanced the cell death inducing effect of the flavonoid luteolin in metastatic squamous cell carcinoma cells. PloS One. 2012; 7:e48264.

20. Coker-Gurkan A, Arisan ED, Obakan P, Guvenir E, Unsal NP. Inhibition of autophagy by 3-MA potentiates purvalanol-induced apoptosis in Bax deficient HCT 116 colon cancer cells. Exp Cell Res. 2014; 328:87-98.

21. Choi YK, Cho SG, Woo SM, Yun YJ, Park S, Shin YC, Ko SG. Herbal extract SH003 suppresses tumor growth and metastasis of MDA-MB-231 breast cancer cells by inhibiting STAT3-IL-6 signaling. Mediat Inflamm. 2014; 2014:492173.

22. Cho WC, Leung KN. In vitro and in vivo anti-tumor effects of Astragalus membranaceus. Cancer Lett. 2007; 252:43-54.

23. Auyeung KK, Ko JK. Novel herbal flavonoids promote apoptosis but differentially induce cell cycle arrest in human colon cancer cell. Invest New Drug. 2010; 28:1-13.

24. Lee HJ, Lee HJ, Lee EO, Lee JH, Lee KS, Kim KH, $\mathrm{Kim} \mathrm{SH}, \mathrm{Lu}$ J. In vivo anti-cancer activity of Korean Angelica gigas and its major pyranocoumarin decursin. Am J Chin Med. 2009; 37:127-142.

25. Shin JW, Son JY, Kang JK, Han SH, Cho CK, Son CG. Trichosanthes kirilowii tuber extract induces G2/M phase arrest via inhibition of tubulin polymerization in HepG2 cells. J Ethnopharmacol. 2008; 115:209-216.

26. Ni L, Zhu X, Gong C, Luo Y, Wang L, Zhou W, Zhu S, Li Y. Trichosanthes kirilowii fruits inhibit non-small cell lung cancer cell growth through mitotic cell-cycle arrest. Am J Chin Med. 2015; 43:349-364.

27. Kim SR, Seo HS, Choi HS, Cho SG, Kim YK, Hong EH, Shin YC, Ko SG. Trichosanthes kirilowii Ethanol Extract and Cucurbitacin D Inhibit Cell Growth and Induce Apoptosis through Inhibition of STAT3 Activity in Breast Cancer Cells. Evid Based Complement Alternat Med. 2013; 2013:975350.

28. Shen S, Niso-Santano M, Adjemian S, Takehara $T$, Malik SA, Minoux H, Souquere S, Marino G, Lachkar S, Senovilla L, Galluzzi L, Kepp O, Pierron G, et al. Cytoplasmic STAT3 represses autophagy by inhibiting PKR activity. Mol Cell. 2012; 48:667-680.

29. Bromberg J. Stat proteins and oncogenesis. J Clin Invest. 2002; 109:1139-1142.

30. Leslie K, Gao SP, Berishaj M, Podsypanina K, Ho H, Ivashkiv L, Bromberg J. Differential interleukin-6/Stat3 
signaling as a function of cellular context mediates Rasinduced transformation. Breast Cancer Res. 2010; 12:R80.

31. Chan LL, Shen D, Wilkinson AR, Patton W, Lai N, Chan E, Kuksin D, Lin B, Qiu J. A novel image-based cytometry method for autophagy detection in living cells. Autophagy. 2012; 8:1371-1382.

32. Komatsu M, Kurokawa H, Waguri S, Taguchi K, Kobayashi A, Ichimura Y, Sou YS, Ueno I, Sakamoto A, Tong KI, Kim M, Nishito Y, Iemura S, et al. The selective autophagy substrate p62 activates the stress responsive transcription factor Nrf2 through inactivation of Keap1. Nat Cell Biol. 2010; 12:213-223.

33. Raben N, Shea L, Hill V, Plotz P. Monitoring autophagy in lysosomal storage disorders. Methods Enzymol. 2009; 453:417-449.

34. Yang Z, Klionsky DJ. Mammalian autophagy: core molecular machinery and signaling regulation. Curr Opin Cell Biol. 2010; 22:124-131.

35. Sharma S, Guthrie PH, Chan SS, Haq S, Taegtmeyer H. Glucose phosphorylation is required for insulin-dependent mTOR signalling in the heart. Cardiovasc Res. 2007; 76:71-80.

36. Yang YP, Hu LF, Zheng HF, Mao CJ, Hu WD, Xiong KP, Wang F, Liu CF. Application and interpretation of current autophagy inhibitors and activators. Acta Pharmacol Sin. 2013; 34:625-635.

37. Liu L, Yang M, Kang R, Wang Z, Zhao Y, Yu Y, Xie M, Yin X, Livesey KM, Lotze MT, Tang D, Cao L. HMGB1induced autophagy promotes chemotherapy resistance in leukemia cells. Leukemia. 2011; 25:23-31.

38. Mathew R, Karp CM, Beaudoin B, Vuong N, Chen G, Chen HY, Bray K, Reddy A, Bhanot G, Gelinas C, Dipaola RS, Karantza-Wadsworth V, White E. Autophagy suppresses tumorigenesis through elimination of p62. Cell. 2009; 137:1062-1075.

39. Linares JF, Amanchy R, Greis K, Diaz-Meco MT, Moscat J. Phosphorylation of $\mathrm{p} 62$ by cdk 1 controls the timely transit of cells through mitosis and tumor cell proliferation. Mol Cell Biol. 2011; 31:105-117.
40. Guo X, Dong Y, Yin S, Zhao C, Huo Y, Fan L, Hu H. Patulin induces pro-survival functions via autophagy inhibition and p62 accumulation. Cell Death Dis. 2013; 4:e822.

41. Yokoyama T, Kondo Y, Kondo S. Roles of mTOR and STAT3 in autophagy induced by telomere 3' overhang-specific DNA oligonucleotides. Autophagy. 2007; 3:496-498.

42. Yokogami K, Wakisaka S, Avruch J, Reeves SA. Serine phosphorylation and maximal activation of STAT3 during CNTF signaling is mediated by the rapamycin target mTOR. Curr Biol. 2000; 10:47-50.

43. Yamada E, Bastie CC, Koga H, Wang Y, Cuervo AM, Pessin JE. Mouse skeletal muscle fiber-type-specific macroautophagy and muscle wasting are regulated by a Fyn/STAT3/Vps34 signaling pathway. Cell Rep. 2012; 1:557-569.

44. Yuan HX, Russell RC, Guan KL. Regulation of PIK3C3/ VPS34 complexes by MTOR in nutrient stress-induced autophagy. Autophagy. 2013; 9:1983-1995.

45. You L, Wang Z, Li H, Shou J, Jing Z, Xie J, Sui X, Pan H, Han W. The role of STAT3 in autophagy. Autophagy. 2015; 11:729-739.

46. Bjorkoy G, Lamark T, Brech A, Outzen H, Perander M, Overvatn A, Stenmark H, Johansen T. p62/SQSTM1 forms protein aggregates degraded by autophagy and has a protective effect on huntingtin-induced cell death. J Cell Biol. 2005; 171:603-614.

47. Kreuzaler PA, Staniszewska AD, Li W, Omidvar N, Kedjouar B, Turkson J, Poli V, Flavell RA, Clarkson RW, Watson CJ. Stat 3 controls lysosomal-mediated cell death in vivo. Nat Cell Biol. 2011; 13:303-309.

48. Singh K, Sharma A, Mir MC, Drazba JA, Heston WD, Magi-Galluzzi C, Hansel D, Rubin BP, Klein EA, Almasan A. Autophagic flux determines cell death and survival in response to Apo2L/TRAIL (dulanermin). Mol Cancer. 2014; 13:70. 